\title{
APLICACIONES DE LA TERMOGRAFÍA INFRARROJA Y LA ESPECTRORRADIOMETRÍA EN EL ESTUDIO DEL DETERIORO DEL PATRIMONIO ARQUITECTÓNICO NACIONAL
}

\author{
(THERMOGRAPHY AND SPECTRORADIOMETRY APPLICATIONS IN THE STUDY OF \\ THE DETERIORATION OF OUR NATIONAL ARCHITECTURAL HERITAGE)
}

J. A. Cusidó, M. Devant y J. Riba

Institut de Tecnología i Modelització Ambiental (UPC)

Cataluña

ESPAÑA

\section{RESUMEN}

Son conocidos los problemas que la acción de los agentes atmosféricos causan a nuestro patrimonio monumental. Sin duda, el aumento de la contaminación atmosférica contribuye a aumentar las causas naturales del deterioro de las piedras que constituyen nuestro legado histórico.

Lamentablemente, el conocimiento cientifico parcial de las causas que producen el denominado "mal de piedra", ha conllevado a restauraciones inapropiadas que, en no pocas ocasiones, lejos de solucionar el problema, han incrementado el proceso de deterioro o degradación.

La necesidad de encontrar métodos de diagnóstico rápidos y eficientes, especialmente los denominados como técnicas de análisis no destructivos, ha dado lugar a la aplicación de la Termografia Infrarroja (TIR) y la Espectrorradiometria (ER) como herramientas de apoyo al estudio del deterioro de las piedras monumentales y cuyos primeros resultados presentamos en este trabajo.

Palabras clave: legado histórico, edificios, termografia, espectrorradiometría
Fecha de recepción: $22-\mathrm{V}-96$

\section{SUMMARY}

It is well known the problems in ancient monumental buildings caused by atmospheric agents. Besides of natural causes, the rise in the atmospheric contamination levels has played an important role in the deterioration of the stones of our national heritage art.

Regrettably the partial scientific knowledge of the causes that produced the called "stone disease", has taken to inappropiate restorations that far from solving the problem, they have increased the deterioration process.

The need of finding quick and efficient diagnostic methods, specially non-destructive analysis techniques, has originated the use of Infrared Thermography and Spectroradiometry as support tools in the study of the deterioration of monumentals stones. The firsts results are presented in this work.

Keywords: heritage art, buildings, thermography, spectrorradiometry. 


\section{Introducción}

Lamentablemente, el patrimonio monumental histórico, y especialmente aquél que se halla situado en los ambientes urbanos, sufre, a menudo, del denominado "mal de piedra". Esto es, la alteración de las características primitivas de la roca, debida a su adaptación a las nuevas condiciones ambientales en que se encuentra. Alteración que, en ambientes urbanos, es agravada por los altos índices de contaminación atmosférica. En algunos casos se han alcanzado tales grados de deterioro que han exigido programas especificos y urgentes de actuación, para poner a salvo la integridad del monumento (como es el caso de la Catedral de Burgos).

$\mathrm{Al}$ emprender las tareas de restauración de un monumento es de vital importancia conocer las causas de su degradación, así como el proceso que ha seguido a lo largo de los años. Para su investigación cobran gran importancia las técnicas no destructivas de análisis, puesto que éstas no significan ningún tipo de actuación sobre el monumento o destrucción de la muestra extraída de él. En este trabajo se presentan los resultados iniciales de la aplicación de la Termografía Infrarroja (TIR) y de la Espectrorradiometría (ER) para el estudio del estado y grado de alteración de las piedras monumentales de la Catedral de Oviedo. En este sentido, se hace hincapié en que se trata de primeros resultados no concluyentes.

\section{La Catedral de San Salvador de Oviedo}

La Iglesia Catedral de San Salvador de Oviedo es una muestra del gótico tardío, de innegable interés históricoartístico, puesto que en él se refleja toda la evolución del gótico en España. Su construcción se realizó sobre antiguos restos románicos y pre-románicos, datando las partes más antiguas del año 1293 (Sala Capitular). Cabe reseñar que su mayor parte es edificada a lo largo de los siglos XV y XVI. A partir del siglo XVII las intervenciones en ella se producen, fundamentalmente, para restaurar partes maltrechas por accidentes meteorológicos (caidas de rayos y vendavales). Mención aparte merece el claustro. Éste, consta de dos pisos: el inferior, construido en el siglo XIV y de estilo gotico, claustro bajo, y el piso superior, claustro alto, que data del siglo XVIII.

En la actualidad, la Catedral de San Salvador presenta un nivel elevado de alteración de la piedra con que fue construida (1), destacando la intensa degradación del claustro y del pórtico, amén del ennegrecimiento de la parte externa de la Catedral. Esto último es debido, generalmente, a la formación de una o más pátinas de suciedad, permaneciendo la roca debajo de ellas inalterada, aunque a menudo decolorada. En las partes más resguardadas y con acceso al exterior, como el pórtico o el claustro, el ennegrecimiento se debe a una alteración efectiva de la piedra, con la formación de costras que, al llegar a cierto espesor, se desprenden en forma de desconchados y deplacaciones.

La Catedral está construida, fundamentalmente, con tres tipos distintos de piedras: Laspra, Piedramuelle y Tiñana, siendo las tres de procedencia de canteras situadas en Asturias (2) (3) (Figura 1). De las tres, la predominante resulta ser la primera ( $60 \%$ del total de la parte gótica), que fue además la primera en ser usada. La Piedramuelle no es utilizada hasta finales del siglo XV y representa un $37 \%$ del material. Por su parte, la piedra Tiñana es utilizada sólo en reconstrucciones realizadas a partir del año 1943, representando tan sólo el 3\% del material total.

La piedra de Laspra es una dolomía micrítica, constituida esencialmente por dolomita, cuarzo y filosilicatos, con unos porcentajes del $90 \%, 5 \%$ y $4,5 \%$, respectivamente. La Piedramuelle y la Tiñana, petrológicamente, pueden ser clasificadas como calizas bioclásticas. Los análisis cuantitativos (2) de la primera han dado como resultado una composición del $85 \%$ de calcita, un 5\% de cuarzo, 5\%de feldespatos y $4 \%$ de filosilicatos. A diferencia, en la Tiñana, no se encuentran feldespatos, siendo su composición la siguiente: $90 \%$ de calcita, $7 \%$ de cuarzo y $2 \%$ de filosilicatos.

En relación al estudio alterológico de las piedras, resulta de suma importancia conocer las propiedades y características macro y microporosas de las rocas, debido a su determinante influencia en los procesos de deterioración que éstas seguirán, siendo de gran importancia, tanto la cantidad de poros como el grado de comunicación entre sí (porosidadabierta). Las tres rocas han resultado poseer una elevada porosidad. En cuanto al tamaño del poro, cabe reseñar que todas resultan ser esencialmente microporosas (radio de acceso menor que $7,5 \mu \mathrm{m}$ ). Las características microporosas de las tres variedades se resumen en la Tabla 1.

Cabe resaltar el elevado porcentaje que la porosidad atrapada (poros de difícil acceso, cuellos de botella) representa respecto al total, con valores del $60 \%$ para la piedra de Tiñana y Piedramuelle y del $40 \%$ para la piedra de Laspra.

\section{Técnicas de análisis no destructivo: Termografía Infrarroja y Espectrorradiometría}

\subsection{Principios fisicos}

Obviamente, la acometida de un proyecto de restauración de un edificio histórico, y especialmente aquéllos de carácter monumental, exige la realización de un exhaustivo estudio que determine, tanto las propiedades físicas y químicas de los materiales con los que se ha construido, como su estado de alteración. En este contexto, las distintas 


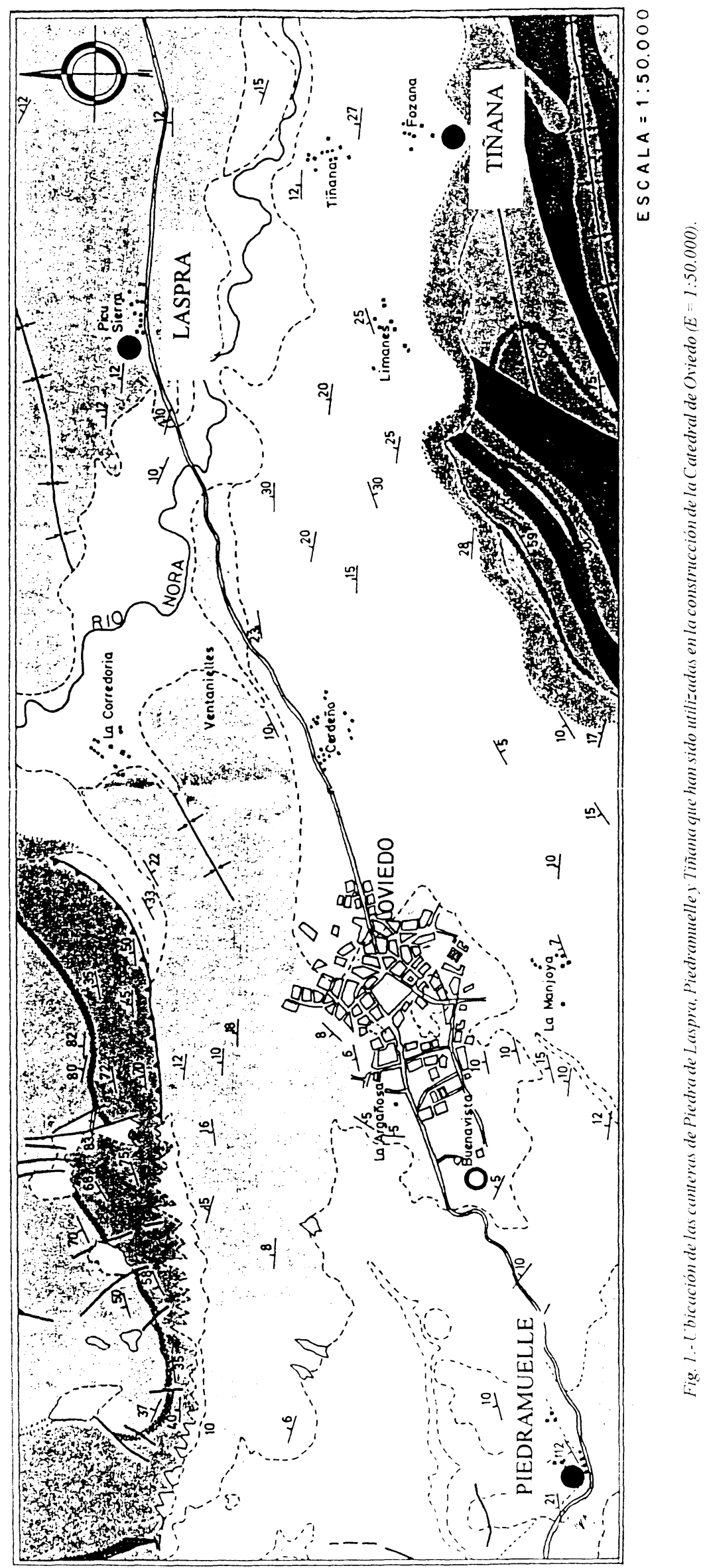




\section{TABLA I}

Resumen de las características microporosas y macroporosas de las Piedras utilizadas en la Catedral de San Salvador de Oviedo. Se destaca el carácter esencialmente microporoso de las tres ( $r$ indica el radio de accesol

\begin{tabular}{||c|c|c|c|c||}
\hline Roca Tipo & $\begin{array}{c}\text { Porosidad } \\
(\%)\end{array}$ & $\begin{array}{c}\text { Macroporosidad } \\
(\mathrm{r}>7,5 \mu \mathrm{m})\end{array}$ & $\begin{array}{c}\text { Microporosidad } \\
(\mathrm{r}<7,5 \mu \mathrm{m})\end{array}$ & $\begin{array}{c}\text { Porosidad } \\
\text { atrapada } \\
(\%)\end{array}$ \\
\hline Laspra & 30,80 & 0,00 & 30,80 & 12,50 \\
\hline Piedramuelle & 24,70 & 2,98 & 21,73 & 15,34 \\
\hline Tiñana & 13,80 & 2,50 & 11,30 & 8,50 \\
\hline
\end{tabular}

técnicas de análisis no destructivo juegan un importante papel por sus ventajas evidentes y, en algunos casos, pueden llegar a constituir un método de diagnóstico rápido. En este artículo presentamos la aplicación de dos de ellas, la Termografía Infrarroja (TIR) y la Espectrorradiometría (ER), al estudio del estado de alteración de la Iglesia Catedral de Oviedo.

Las dos técnicas mencionadas reunen en común el uso de la radiación electromagnética emitida y/o reflejada por el cuerpo en estudio como parámetro de análisis. Una diferencia básica entre las dos técnicas reside en que la ER se orienta al estudio de la radiación reflejada, transmitida o dispersada por un cuerpo o medio, como resultado de la radiación incidente sobre él, emitida por una fuente luminosa externa, en tanto que la TIR se dedica al análisis de la radiación electromagnética en el espectro infrarrojo, emitida por el propio objeto sometido a estudio.

Todos los cuerpos emiten radiación electromagnética en función de la temperatura a la que se encuentran, por este motivo recibe el nombre de radiación térmica. La radiación total emitida viene dada por la ley de Stefan-Boltzmann:

$$
\mathrm{R}_{\mathrm{t}}=\varepsilon \cdot \sigma \cdot \mathrm{T}^{4}\left(\mathrm{Wm}^{-2}\right)
$$

donde $\sigma$ es la constante de Stefan-Boltzmann $\left(5,67 \cdot 10^{-8}\right.$ $\mathrm{Wm}^{-2} \mathrm{~K}^{-4}$ ) y $\varepsilon$ es la emisividad del material en cuestión. Ésta se define como el cociente entre la radiación emitida por el cuerpo en cuestión con la que emitiría un cuerpo negro (aquél que absorbe toda la radiación incidente) a su misma temperatura (por tanto, para los cuerpos negros $\varepsilon=1$ ). La emisividad depende de la longitud de onda y de la temperatura. Los cuerpos en que se cumple la relación $\varepsilon<1$ se denominan cuerpos grises.

La radiación emitida no es constante para todas las longitudes de onda; su distribución espectral cumple la ley de Planck

$$
\frac{\mathrm{dR}(\lambda, \mathrm{T})}{\mathrm{d} \lambda}=\frac{2 \pi \mathrm{c} \varepsilon(\lambda, \mathrm{T})}{\mathrm{e}^{\frac{\mathrm{hc}}{\lambda \mathrm{k} T}}-1}
$$

En la Figura 2 se representan los espectros de radiación emitida para un cuerpo negro a diferentes temperaturas. Se observa que para temperatura ambiente (alrededor de $297^{\circ} \mathrm{K}$ ) el máximo de radiación se produce para longitudes de onda situadas en la banda del espectro infrarrojo, y más concretamente en la banda del infrarrojo cercano o mediano, comprendida entre los valores de longitud de onda entre $700 \mathrm{~nm}$ y $20.000 \mathrm{~nm}$.

Aparte de la emisividad hay otros factores que influyen de manera importante en la medida de la radiación térmica emitida por un cuerpo. En primer lugar, hay que tener en cuenta que la radiación que llega al detector está compuesta, además de la radiación propiamente emitida, por la radiación reflejada proveniente de otros cuerpos o de fuentes luminosas externas. Habría, pues, que reducir al máximo estas radiaciones "parásitas", ya que pueden dar lugar a temperaturas aparentes superiores a las reales, como en el caso de una esquina a causa de las reflexiones mutuas entre las dos paredes que la forman.

También influye el ángulo de incidencia de la observación (4), puesto que la emisividad de un material varía con la dirección de la misma, (cuerpos no-lambertianos), haciéndose nula para ángulos rasantes. Tan sólo para los cuerpos negros y grises la emisividad es la misma, sea cual sea el ángulo de observación. En la práctica, los metales tienen una emisividad constante hasta un ángulo de $40^{\circ}$, y los dieléctricos hasta los $60^{\circ}$.

Finalmente, la atmósfera, el medio en el que se transmite la radiación térmica, influye absorbiendo o dispersando parte de ella. En este sentido, cabe resaltar la existencia de ventanas de transmisión, es decir, intervalos de longitudes 


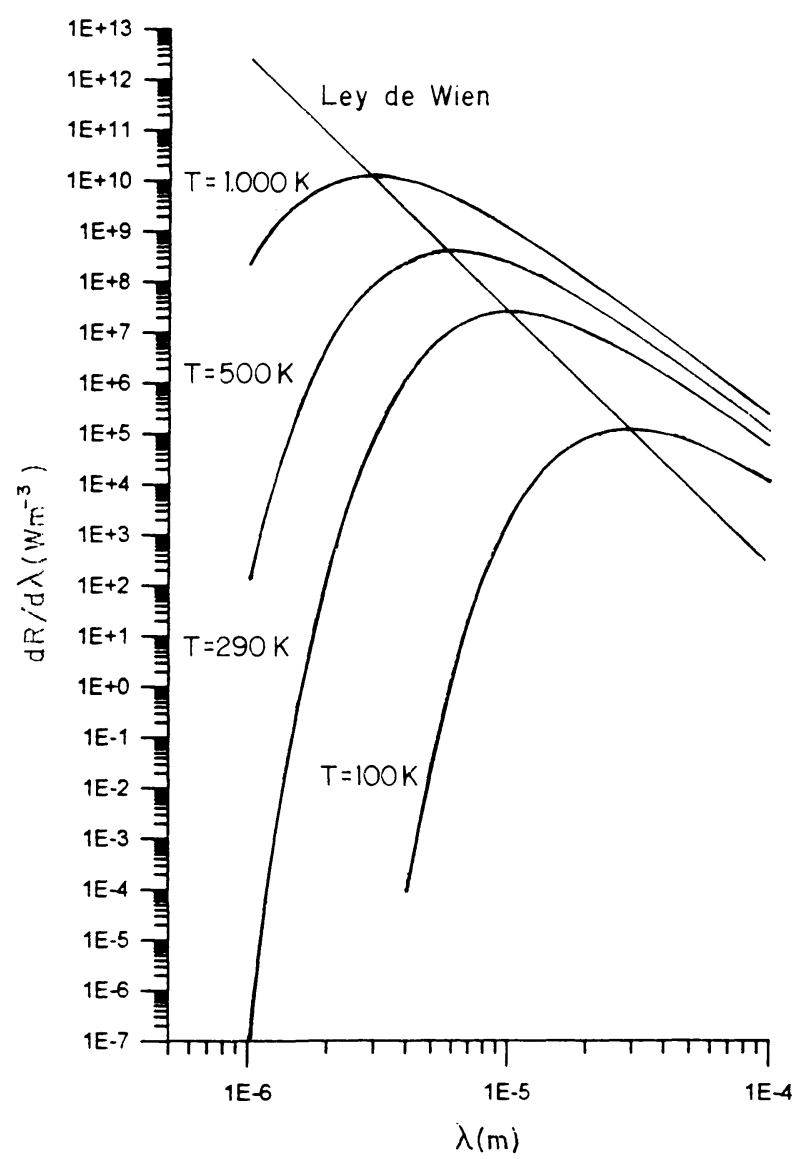

Fig. 2.- Representación, en escala logarítmica, de la radiación emitida por un cuerpo negro a diferentes temperaturas, según la Ley de Planck. Se observa que para temperaturas próximas a la ambiente $\left(290^{\circ} \mathrm{K}\right)$, el máximo de emisión corresponde al rango del infrarrojo, según la línea descrita por la Ley de Wien $\left(\lambda_{m} T=\right.$ cte. $)$.

de onda para los que la atmósfera es prácticamente transparente. Entre éstas existen las situadas entre los 8 y $13 \mu \mathrm{m}$ que, precisamente, corresponde con la longitud de onda del máximo de emisión para cuerpos situados a temperatura ambiente, según la conocida expresión de la ley de Wien representada, asimismo, en la Figura 2.

\subsection{Termografia Infrarroja (TIR)}

LaTermografía Infrarroja(TIR)es una técnica instrumental que convierte una determinada distribución espacial de radiación térmica, esto es, una señal en la banda infrarroja del espectro elctromagnético, invisible para el ojo humano, en señales eléctricas computerizables ("pixels"), generando una imagen visible. Intervienen dos parámetros en la medida: temperatura y emisividad. Para realizar medidas cuantitativas es necesario conocer previamente una de las dos, aunque cabe resaltar que es mucho más adecuada para realizar medidas cuantitativas de la temperatura (errores de hasta el $5 \%$ ), que para la emisividad (errores de hasta el $30 \%$ ).

LaTIR ofrece una información que corresponde a las capas más superficiales del material. En algunos casos, cuando la radiación incidente sobre el cuerpo está reforzada por una longitud de onda determinada, la radiación electromagnética es capaz de penetrar un cierto espesor y reflejarse en una capa a una determinada, profundidad. Esta radiación reflejada es la que se recoge con la cámara, de forma que somos capaces de "ver" lo que ocurre detrás de la pared (5)

\section{La TIR se caracteriza por:}

-Ser una técnica de medida de temperatura y emisividad superficial sin entrar en contacto directo con el sistema en estudio (denominada, por este motivo, técnica no destructiva).

-Ser una técnica totalmente pasiva, es decir, que no requiere de fuente de iluminación externa, lo cual permite su funcionamiento, tanto diurno como nocturno, asi como efectuar la Inspección Termográfica sin alterar las condiciones ambientales durante la experimentación.

-Ser una técnica ideal para el estudio de las pérdidas energéticas, cuya información se aplica al ahorro y uso racional de la energía, asi como potencialmente a diversas áreas de interés para la preservación medioambiental, como es el caso que nos ocupa.

-Una de sus aplicaciones más relevantes se halla en lo que se denomina diagnóstico o mantenimiento preventivo; se trata de una aplicación creciente de esta herramienta científica. Su capacidad de análisis in situ permite efectuar controles de procesos térmicos, o donde la temperatura y la emisividad de las superficies aporten información válida para el diagnóstico.

-Finalmente, destacamos que se trata de una técnica que proporciona la información en tiempo real, lo que permite una gran flexibilidad para el estudio de observaciones inesperadas.

Existe un importante campo de aplicaciones de la termografía en el estudio del estado del patrimonio arquitectónico y monumental (5). Entre las que citamos:

-Establecimiento cronológico de las diferentes fases constructivas, pues permite diferenciar puertas y ventanas tapiadas o abiertas posteriormente, la estructura de los muros, los diferentes materiales utilizados, etc.

-Localizar el paso de canalizaciones diversas y vías de servicios.

-Poner de relieve la presencia de humedades y fenómenos de capilaridad.

- Análisis de irregularidades bajo estucos y frescos. Inhomogeneidades constructivas. 


\subsection{Espectrorradiometria (ER)}

LaER es una técnica de medidade flujo energético, emitido por una fuente de radiación o superficie donde ésta incide, discriminando las diferentes longitudes de onda (lo que constituye el espectro).

Las aplicaciones de la espectrorradiometría se circunscribian, inicialmente, al campo de la química analítica, si bien, posteriormente, el campo de utilidades de dicha técnica se amplió substancialmente con las posibilidades de los avances de la microelectrónica, desarrollados durante los últimos años, que permitieron la fabricación de instrumentación de dimensiones reducidas, de fácil manejabilidad y de simple mantenimiento.

En este sentido, en las posibles aplicaciones científicas, citamos:

-Energía Solar. Análisis espectral de la radiación solar.

-Medio Ambiente. Contaminación de recursos acuosos.

-Medio Ambiente. Patologías en construcción, vegetación, etc.

-Teledetección. Análisis de imágenes de satélites.

-Termografia. Apoyo a la teledetección infrarroja.

-Colorimetría. Sistema C.I.E.

-Análisis de la emisión radiante de fuentes luminosas.

-Absorción en gases, líquidos y sólidos.

Usualmente, el uso de esta técnica, en su versión instrumental de campo, se ha circunscrito a la determinación de la respuesta espectral de la vegetación (determinación de espectros de reflexión de plantas (7), de suelos, así como de la determinación del espectro solar incidente (albedo) en determinadas aplicaciones de la energía solar (8).

Sin embargo, consideramos que existen posibilidades de aplicación en otros campos como la petrofísica, por cuanto la respuesta espectral, junto con la utilización de otras técnicas físicas, puede correlacionarse con la difusión de determinados agentes ambientales que inciden en la alteración de las rocas de nuestro patrimonio monumental. En concreto, entendemos que las variaciones sobre las propiedades físicas, que inciden sobre el deterioro de las piedras, en que esta técnica puede ser interesante son las siguientes:

- Determinación del color (Sistema C.I.E.).

- Velocidades de absorción y desorción.
- Permeabilidad al vapor.

-Expansión térmica.

Sin embargo, la falta de referencias, al ser esta investigación una de las primeras aplicaciones a la petrografia, sugiere que los resultados obtenidos con esta técnica, dentro del marco general de nuestro trabajo, deberán atenerse a la consideración de datos iniciales no concluyentes.

\section{Metodología y plan de trabajo}

\subsection{Termografia Infrarroja (TIR)}

Los días 18 de marzo de 1993 y 2 de junio de 1994 se realizaron sendas inspecciones termográficas in situ. E1 equipo utilizado en las inspecciones constó de

- Equipo termográfico AGEMA 470.

- Termohigrómetro digital Rotronic GTL-100-50.

- Termómetro de contacto Anritsu HL600.

- Estación de trabajo para el tratamiento de imagen de resolución $740 \times 240$ pixels y 4096 colores.

- Estación de edición de vídeos VHS, SONY E300.

La metodología seguida en estas inspecciones consta de tres fases: fase de recopilación de datos iniciales, la fase de la inspección termográfica propiamente dicha y la fase de análisis de los datos obtenidos.

En la primera fase, a tenor de los datos suministrados y obtenidos en otros análisis, se realiza una selección de los lugares donde debe realizarse la inspección termográfica. La selección se realizó en base a tres criterios:

i) El grado de alteración.

ii) Diferentes características pétreas (piedra de Laspra o Piedramuelle).

iii) Variabilidad en la ubicación (orientación, exposición a agentes meteorológicos, etc).

En la Catedral de Oviedo se seleccionaron tres áreas: El patio de los de los Reyes, la terraza del Rosetón frontal, y el Claustro.

En la segunda fase, una vez medidos los datos higrotérmi$\cos$ (Tabla 2), se realiza el barrido por termovisión, con un registro videográfico y digital de la información obtenida.

Finalmente, en la evaluación de los resultados, se realiza un tratamiento informático de las imágenes más relevantes.

\subsection{Espectrorradiometria (ER)}

Con el objetivo de desarrollar una técnica que permita evaluar el grado de alteración de una roca en profundidad, 
TABLA ॥

Condiciones climáticas durante las inspecciones termográficas realizadas

\begin{tabular}{||c|c|c|c|c|c|c||}
\hline \multirow{2}{*}{} & \multicolumn{2}{|c|}{ Patio de los Reyes } & \multicolumn{2}{c|}{ Terraza del Rosetón } & \multicolumn{2}{c|}{ Claustro de la Catedral } \\
\cline { 2 - 7 } & $\mathrm{T}\left({ }^{\circ} \mathrm{C}\right)$ & $\mathrm{HR}(\%)$ & $\mathrm{T}\left({ }^{\circ} \mathrm{C}\right)$ & $\mathrm{HR}(\%)$ & $\mathrm{T}\left({ }^{\circ} \mathrm{C}\right)$ & HR $(\%)$ \\
\hline $18 / 3 / 93$ & $13-16$ & $55( \pm 3)$ & 18 & $53( \pm 2)$ & 15 & $67( \pm 3)$ \\
\hline $2 / 6 / 94$ & 23 & $65( \pm 3)$ & 20 & $68( \pm 3)$ & 20 & $68( \pm 3)$ \\
\hline
\end{tabular}

se realizaron los análisis de los espectros de reflexión de una serie a tres profundidades diferentes $(0,1$ y $5 \mathrm{~cm})$ de dos muestras de Piedra Laspray tres de Piedramuelle. Las medidas se realizaron con un espectrorradiómetro LICOR 1800 , que proporciona un rango de medida de 400 a 1100 $\mathrm{nm}$, correspondientes a las bandas visible y del infrarrojo medianodel espectroelectromagnético, con un intervalo de $2 \mathrm{~nm}$. Su sensibilidad es de $1,5 \cdot 10^{-7} \mathrm{Wcm}^{-2} \mathrm{~nm}^{-1} \mathrm{ster}^{-1}$.

\section{Resultados}

\subsection{Termografia Infrarroja}

La Termografia Infrarroja permite distinguir, como ya se ha dicho, zonas a diferente temperatura o emisividad. En las Figuras 3 y 4(A y B), correspondientes a la terraza del Rosetón Central en la Fachada Principal, se observa cómo se destacan pequeñas áreas bien definidas a una temperatura claramente superior (alrededor de $1^{\circ} \mathrm{C}$ ) del resto del

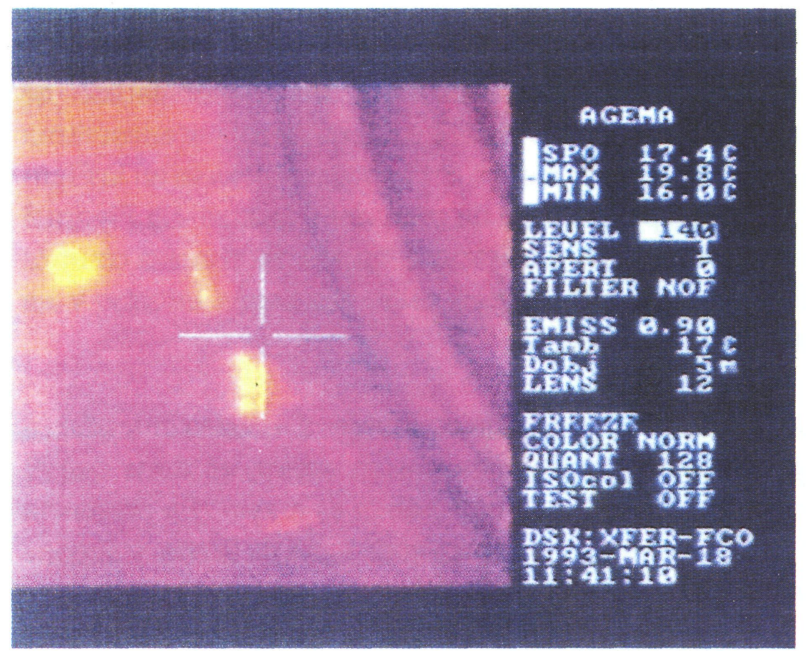

Fig. 3.- Termograma que corresponde al área del Rosetón Central en que se pone en evidencia las restauraciones efectuadas, distinguiendo el material original del utilizado en las mismas por su mayor contraste térmico.
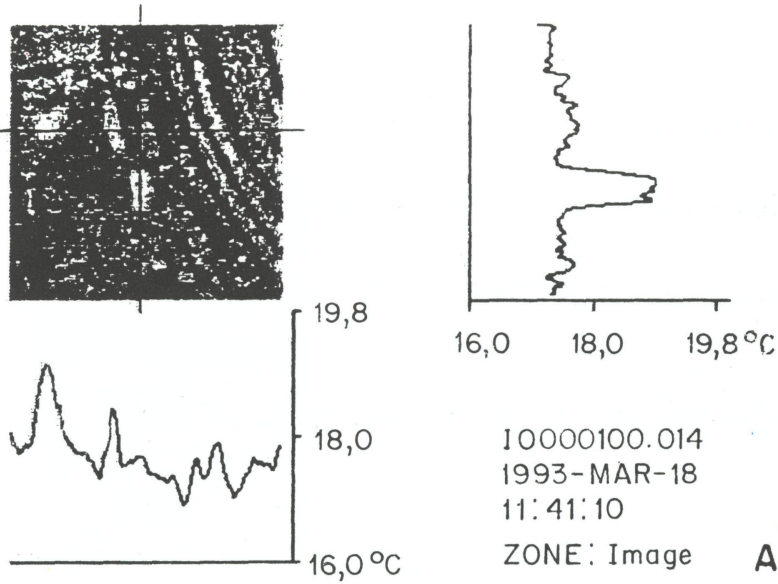

10000100.014 1993-MAR-18 $11: 41: 10$

ZONE: Image

A)
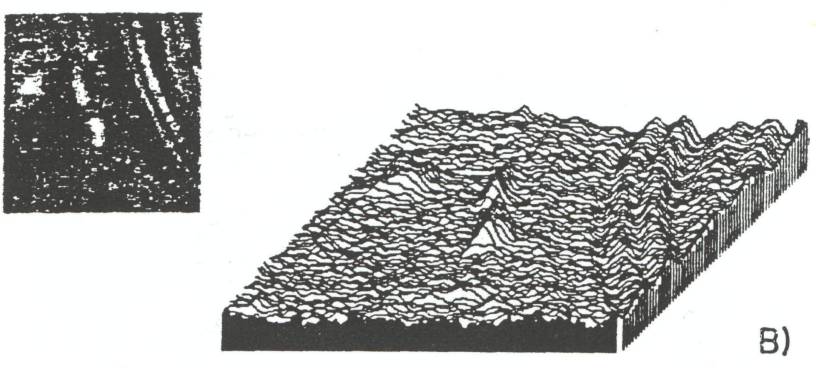

Fig. 4.- A) Perfil de temperatura, y B) mapa de temperaturas del área recogida en el termograma de la Fig. 3.

muro. Las diferencias observadas son causa de intervenciones de restauración, realizadas en la segunda mitad de este siglo, y con un material diferente al original. Esto constituye un claro ejemplo de la capacidad de la técnica de la termografía infrarroja para la determinación, estudioy seguimiento de las actuaciones de restauración.

En otros casos, la TIR, permite distinguir sillares de un 
mismo material con un distinto grado de alteración. La Figura 5 presenta las imágenes termográficas de bloques localizados en las paredes Sur y Norte, respectivamente, del Patio de los Reyes, con unas diferencias de temperatura entre 3 y $1{ }^{\circ} \mathrm{C}$ respecto a sus contiguos. En el primer caso, las zonas más frías pertenecen a zonas de un nivel de degradación más elevado. El corte de cantera y la colocación en obra pueden causar variaciones en la emisividad. Éste puede ser el caso de sillares aislados. Sin embargo, cuando el área que presenta la inhomogeneidad, o la diferencia de temperatura es considerable, las posibles diferencias de , emisividad no pueden ser las únicas causantes. En este sentido, en la Figura 6 (A y B) se presenta una cornisa de un pilar situado en el lado Sur del Claustro, que la termografia revela como una zona fuertemente alterada, aunque en primera aproximación sólo aparecía ligeramente degradada.

Particularmente interesante resulta la observación de las zonas de lavado, es decir de aquéllas en que la acción de la
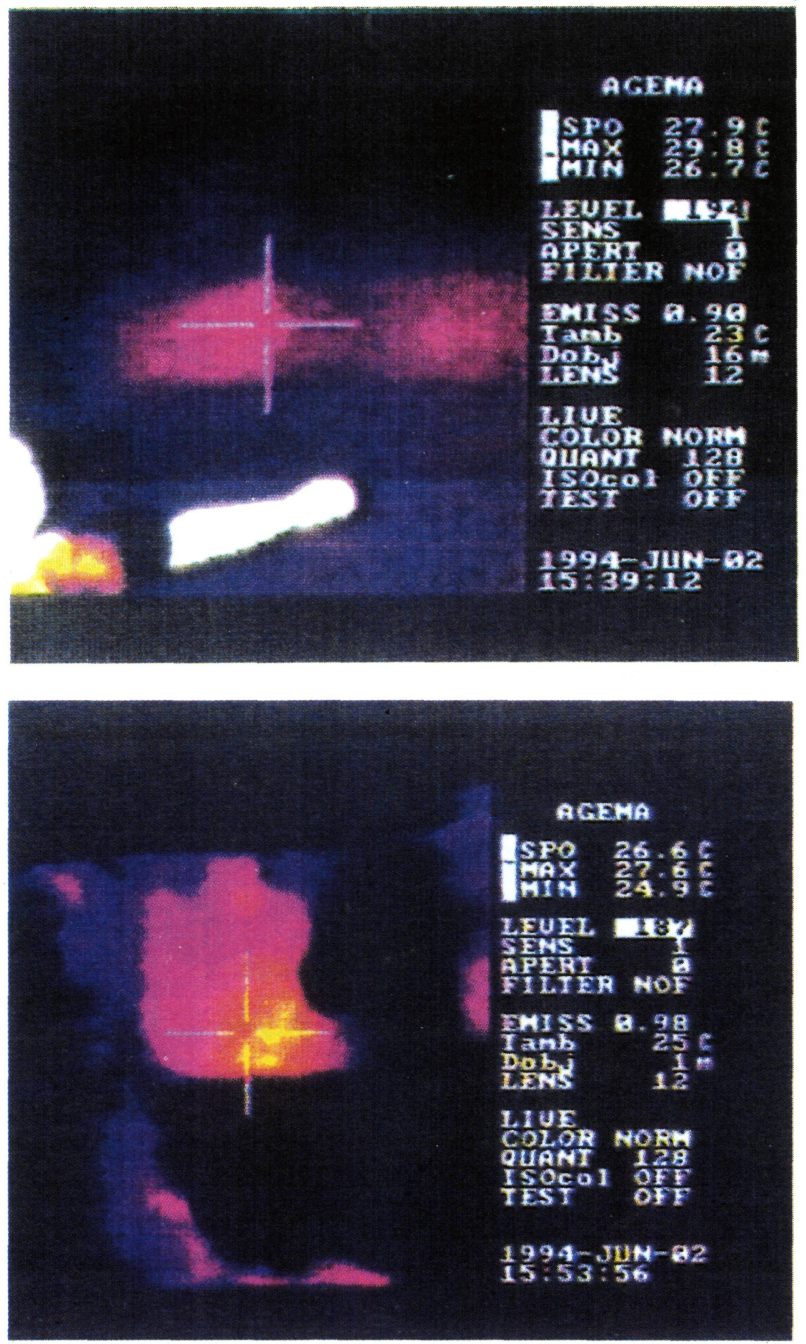

Fig. 5.- Termogramas correspondientes a las paredes Sur y Norte del patio de los Reyes, donde, en cada caso, se pueden observar diferencia de temperaturas entre sillares contiguos de $1^{\circ} \mathrm{C}$ y $3^{\circ} \mathrm{C}$, indicativos de su mayor grado de alteración, independientemente de su observación en imagen visible.

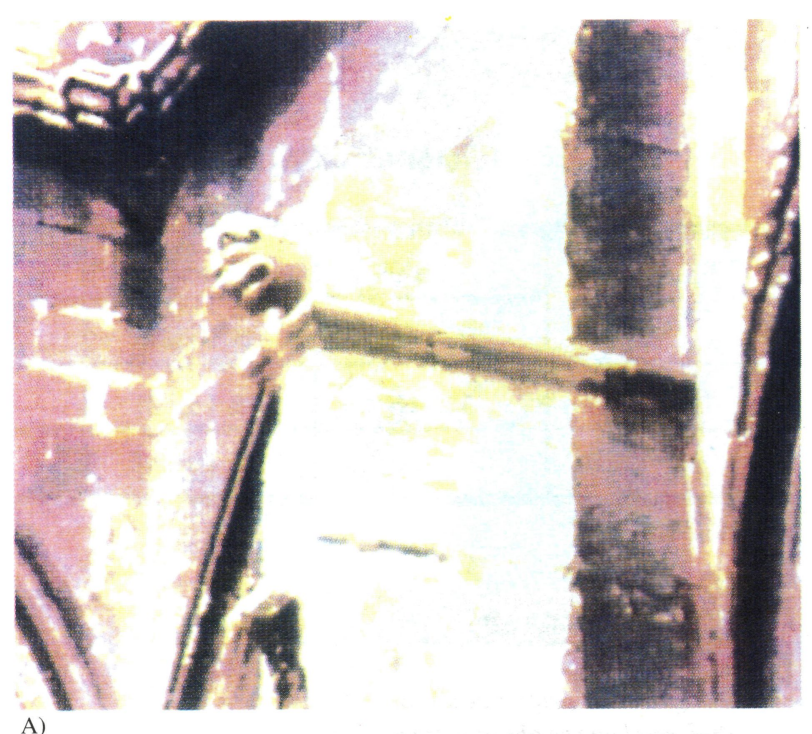

A)

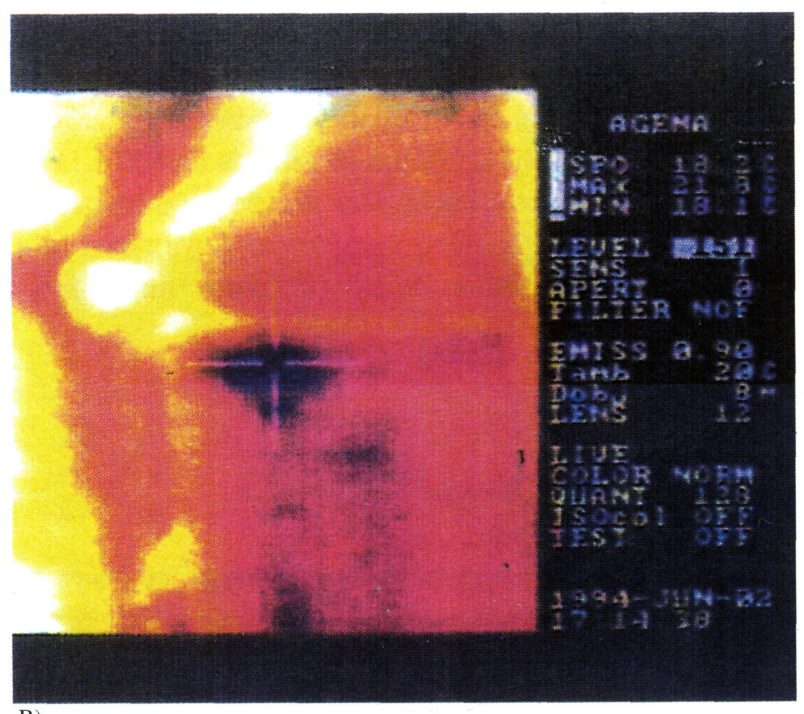

B)

Fig. 6.- A) Imagen visible y B) termográfica de un contrafuerte situado en el Claustro de la Catedral. La imagen termográfica revela una zono fuertemente alterada que, a simple vista, permanece imperceptible.

lluvia ha impedido la formación de pátinas y/o costras. Las zonas lavadas, que presentan un mejor estado de conservación, bajo la termografía infrarroja se encuentran a una temperatura menor, tal y como se observa en la Figura 7, correspondiente a un pilar del Claustro. La Figura 8 corresponde al perfil de temperaturas. Se observa cómo la diferencia de temperatura entre las zonas lavadas y no lavadas llega hasta los $3^{\circ} \mathrm{C}$.

La diferencia encontrada es debida, a nuestro entender, a que las zonas lavadas transpiran mejor, es decir que el índice de evaporación convectiva es mayor. La presencia de costras impide la absorción de agua de lluvia y supone un obstáculo a la evaporación.

Sin embargo, y en contradicción a lo observado en el Claustro, en la terraza del Rosetón Central las zonas lavadas presentan, contrariamente, temperaturas ligeramente más elevadas (Figura 9). 


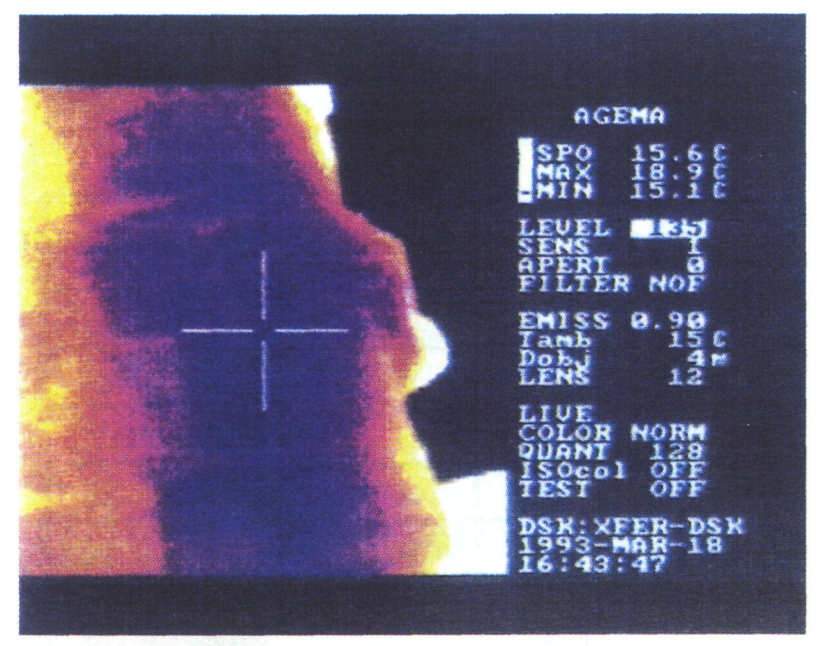

Fig. 7.- Imagen termográfica de un contrafuerte situado en el claustro de la Catedral, en el que se observa cómo las zonas lavadas presentan una temperatura menor (en este sentido se considera que transpiran mejor, lo que tiene un efecto positivo en su menor grado de alteración).
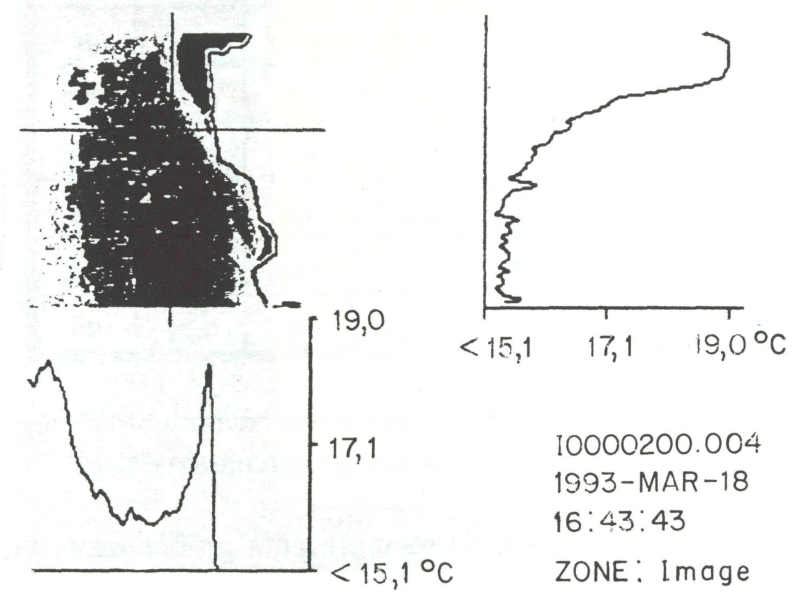

Fig. 8. - Perfil de temperaturas del termograma presentado en la Figura 7. La diferencia de temperaturas entre las zonas lavadas y no lavadas se sitúan en el entorno de los $3^{\circ} \mathrm{C}$.

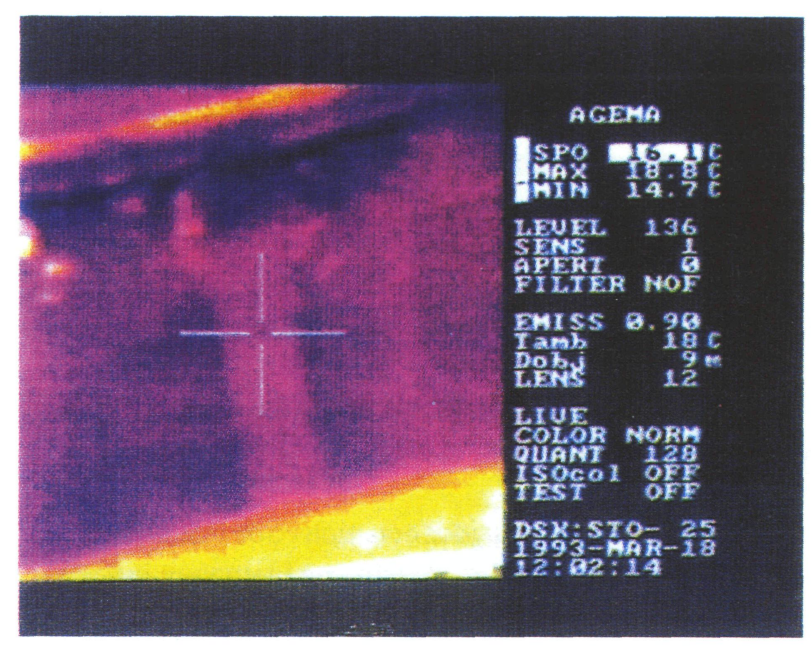

Fig. 9.- Observación del efecto de la acción de lavado por la lluvia sobre algunos elementos situados en la terraza del Rosetón Central, cuya temperatura es ligeramente superior a las restantes, en contradicción a lo observado en el Claustro.

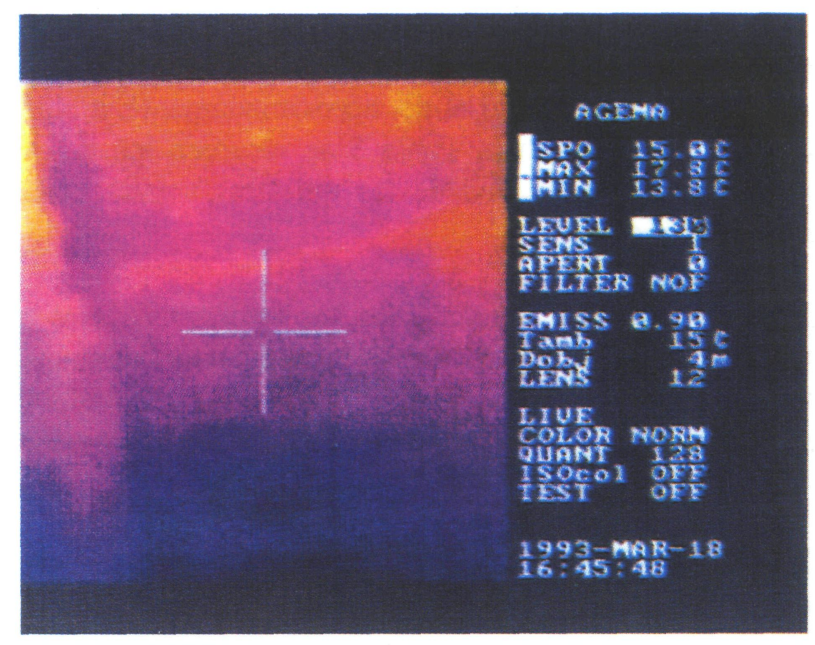

Fig. 10.- Termograma donde se observa el efecto de capilaridad en la parte inferior de un contrafuerte del Claustro de la Catedral.

Este comportamiento diferente puede ser atribuido a diferentes motivos. Por una parte, la exposición a la radiación solar o la existencia de ligeras brisas o vientos, esto es, a las diferentes condiciones microambientales. Por otra parte, cabe recordar que mientras que el Claustro está construido con Piedra de Laspra, la terraza del Rosetón Central está hecha con Piedramuelle. La primera es más porosa y tiene menor porosidad atrapada que la segunda, índice de porosidad total del 30,8\% y de porosidad atrapada del $12,5 \%$ contra el $24,8 \%$ y el $15,3 \%$ respectivamente. Las diferencias en la porosidad permitirián a la piedra de Laspra una evaporación del agua absorbida más efectiva. También puede influir el hecho de que la alteración en la Terraza del Rosetón sea debida a la formación de pátinas, y no de costras, como en el Claustro.

Finalmente, en la Figura 10 se observa la capacidad de la TIR para poner de relieve fenómenos de capilaridad. El termograma corresponde a la base de un contrafuerte del Claustro afectada por dicho fenómeno.

\subsection{Espectrorradiometria (ER)}

En las Figura 11(A y B) presentamos dos de los espectros de reflexión obtenidos para dos de las muestras de las que se dispuso. La primera corresponde a piedra de Laspra y la segunda a Piedramuelle. Destaca la distribución, prácticamente lineal, de los espectros, con pendiente creciente hacia la banda correspondiente al amarillo, que se corresponde, en todos los casos, al color característico de las muestras de las que se partía (blanco-amarillento).

Sin embargo, es interesante observar la formación de pequeños picos a $550 \mathrm{~nm}$ (visible) y $770 \mathrm{~nm}$ (infrarrojo próximo) en las muestras de Piedramuelle, que se definen más claramente según aumenta la profundidad de corte de las diferentes muestras. 
Dado el carácter lineal de los espectros, se opta por el análisis de los mínimos y máximos de reflectancia, los cuales se acaban produciendo, aproximadamente, a los 400 y $1.100 \mathrm{~nm}$. En la Tabla 3 se resumen los datos obtenidos para cada una de las muestras y para cada profundidad escogida.

En todas las muestras estudiadas, los valores máximos y mínimos de las reflectancias se encuentran situados en las muestras cortadas a $1 \mathrm{~cm}$ de profundidad, pudiéndose observar tendencias de.variación cercanas, según se trate de muestras de Laspra o bien de Piedramuelle.

Las mayores variaciones se observan en la piedra de Laspra (en porcentajes muy parecidos en ambas muestras), lo cual se corresponde a su mayor porosidad (capacidad de absorción) respecto a las piedras de Piedramuelle.

En el caso de las muestras de Piedramuelle, la variación parece ser ligeramente menor, cosa que concuerda con el menor grado de alteración de la misma. Parece ser posi-

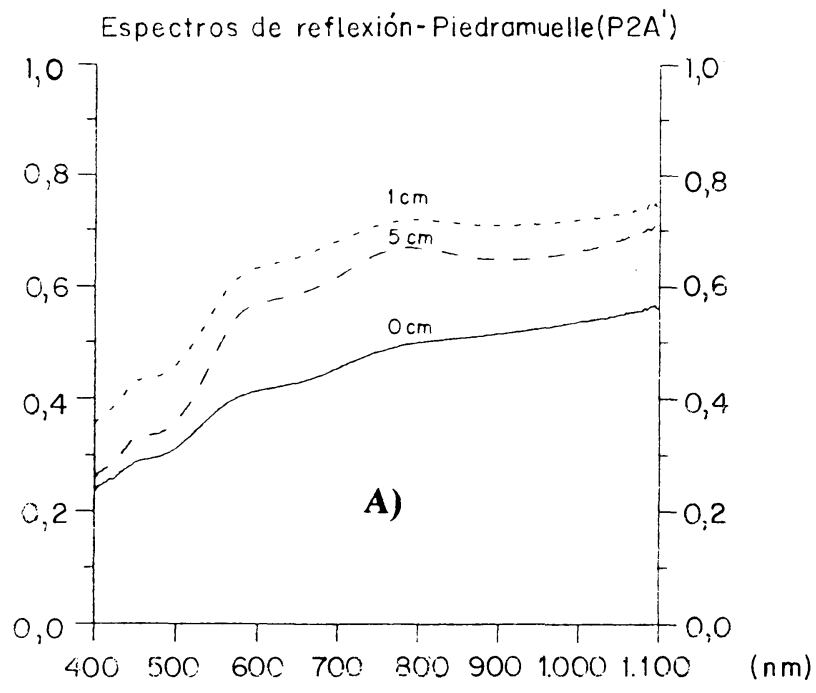

Espectros de reflexión-Piedra de Laspra(L2A')

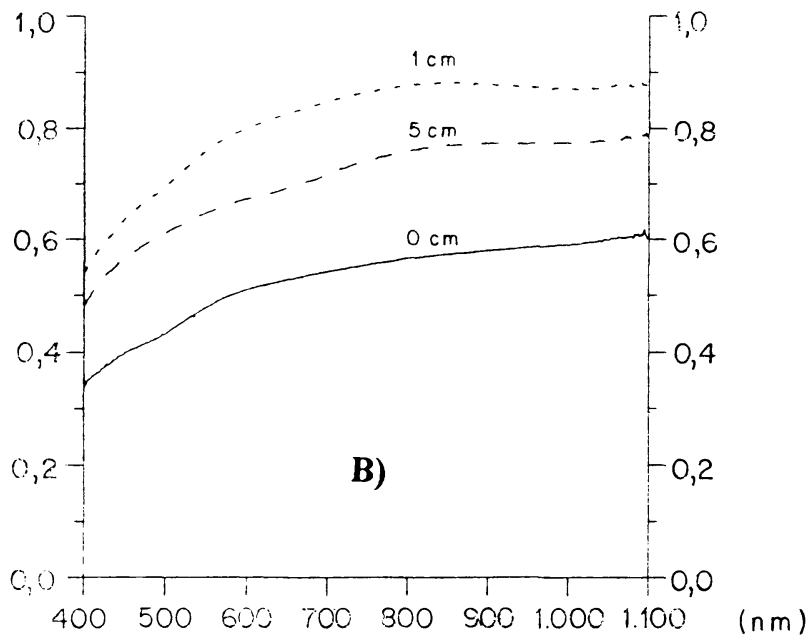

Hig. 11.- Muestras cortadas a $0,1,1.5 \mathrm{~cm}$, han sido estudiadas mediante espectrorradiometria de reflexion. A) Piedra de Laspra. B) Piedramuelle.

\section{TABLA III}

Valores máximos y mínimos de los espectros de reflexión obtenidos de las muestras analizadas a diferentes profundidades de corte

\begin{tabular}{|c|c|c|c|c|c|}
\hline \multirow[t]{2}{*}{ MUESTRA } & \multirow{2}{*}{ Prof. } & \multicolumn{2}{|c|}{$\begin{array}{c}\text { Min } \\
\text { Reflectancia }\end{array}$} & \multicolumn{2}{|c|}{$\begin{array}{c}\text { Máx. } \\
\text { Reflectancia }\end{array}$} \\
\hline & & & $\%$ & & $\%$ \\
\hline \multirow{3}{*}{$\begin{array}{c}\text { Laspra } \\
\text { L2A }\end{array}$} & 0 & 0,23 & 44 & 0,51 & 61 \\
\hline & 1 & 0,52 & 100 & 0,84 & 100 \\
\hline & 5 & 0,46 & 88 & 0,81 & 96 \\
\hline \multirow{3}{*}{$\begin{array}{l}\text { Laspra } \\
\text { L2A' }\end{array}$} & 0 & 0,34 & 63 & 0,62 & 70 \\
\hline & 1 & 0,54 & 100 & 0,88 & 100 \\
\hline & 5 & 0,48 & 88 & 0,79 & 89 \\
\hline \multirow{3}{*}{$\begin{array}{c}\text { Piedramuelle } \\
\text { P1 }\end{array}$} & 0 & 0,16 & 57 & 0,66 & 69 \\
\hline & 1 & 0,28 & 100 & 0,95 & 100 \\
\hline & 5 & 0,26 & 91 & 0,92 & 97 \\
\hline \multirow{3}{*}{$\begin{array}{c}\text { Piedramuelle } \\
\text { P2A }\end{array}$} & 0 & 0,27 & 90 & 0,60 & 85 \\
\hline & 1 & 0,30 & 100 & 0,70 & 100 \\
\hline & 5 & 0,29 & 97 & 0,70 & 100 \\
\hline \multirow{3}{*}{$\begin{array}{c}\text { Piedramuelle } \\
\text { P2A' }\end{array}$} & 0 & 0,24 & 68 & 0,57 & 76 \\
\hline & 1 & 0,35 & 100 & 0,75 & 100 \\
\hline & 5 & 0,26 & 74 & 0,71 & 80 \\
\hline
\end{tabular}

ble comparar las dos situaciones en resistencia a la alteración diferencial entre ambas en un porcentaje del 10\%.

En la Figura 12 (A y B) se representa gráficamente la información resumida en la Tabla 3 . Los resultados obtenidos sugieren la adopción de un modelo de alteración proporcional a la profundidad siguiendo una relación del tipo:

$$
\rho=A+B e^{-k x}
$$

aunque este modelo debería ser refrendado por análisis más detallados que no se han podido realizar en el marco del proyecto.

\section{Conclusiones}

Del trabajo experimental, y a modo de resumen, se concluye que:

I) Los materiales introducidos con motivode restauraciones son fácilmente observables, puesto que la imagen infrarroja aumenta el contraste entre el material original y el introducido en la restauración, debido a sus diferentes propiedades térmicas o emisivas. Para evitar la aparición de patologías, como por ejemplo condensaciones intersticiales, que contribuyan a la degradación de los 

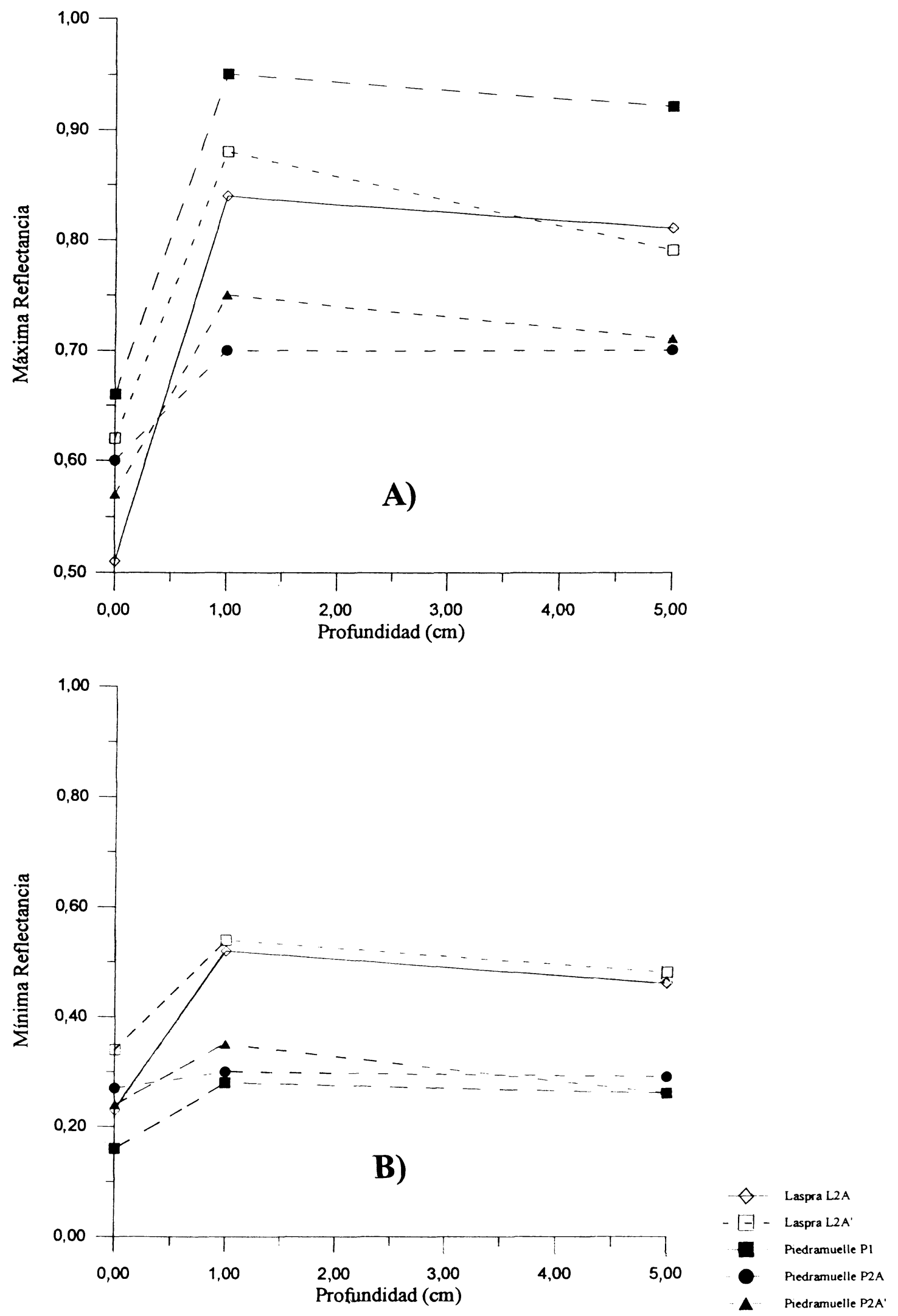

Fig. 12.- En la figura se representan los valores máximos A) y minimos B) de los espectros de reflexión de cada muestra estudiada y por cada profundidad de corte. La variación observada sugiere un posible modelo de alteración del tipo presentado en el texto. 
mismos, las actuaciones de restauración se deberían realizar con materiales de características térmicas similares.

II) Con la TIR se manifiestan, claramente, los materiales alterados de los que no lo están, deduciéndose también de ello que los materiales en buen estado de concervación se encuentran a una temperatura superficial sensiblemente más baja que el resto ("se puede decir que transpiran mejor"). Sin embargo, esto no puede ser generalizado para cualquier situación, pero sí se puede afirmar que, para una situación determinada particular, la TIR permite distinguir zonas de propiedades emisivas diferentes. Con la ayuda de otros análisis se puede determinar su correlación con el grado de alteración. Las imágenes obtenidas permiten, pues, una extrapolación de la alteración para aquel caso concreto, además de permitir realizar una evaluación del área afectada.

III) Algunos bloques del mismo material presentan temperaturas o emisividades superficiales diferentes, que consideramos pueden ser debidas al tipo de corte en cantera. Mediante la TIR, en la fase actual de trabajo, se hace muy difícil evaluar las diferencias de emisividades, ya que el margen de error puede ser del $30 \%$, lo cual incide en el rango de lecturas experimentales.

IV) El análisis espectrorradiométrico permitiría llegar a una técnica de evaluación del grado de alteración de una roca en profundidad, cuya manejabilidad y sensibilidad puede ser de gran servicio en estudios de procesos de alteración y de las piedras monumentales, y que podrían dar lugar a un modelo o escala de alteración.

\section{Agradecimientos}

La realización del presente estudio ha sido llevada cabo con el apoyo de la Comisión Interministerial de Ciencia y Tecnología (CICYT), mediante el contrato Pat.
91.1093-CO2-O2). Los autores desean hacer constar su agradecimiento por la ayuda recibida.

\section{BIBLIOGRAFÍA}

(1) ESBERT, ROSA M y MARCOS, ROSA Ma: Las Piedras de la Catedral de Oviedo y su deterioración. $1^{\text {a }}$ Edición Colegio Oficial de Aparejadores y Arquitectos Técnicos de Asturias. Oviedo 1983.

(2) ESBERT, ROSA M ${ }^{\mathrm{a}}$; MARCOS, ROSA M $\mathrm{M}^{\mathrm{a}}$ y ALONSO, J. La deterioración de las Piedras de la Catedral de Oviedo. $1^{\text {a }}$ Parte: Petrografía y porosidad, características intrínsecas determinantes de la deterioración de sus rocas carbonatadas. Materiales de Construcción, $\mathrm{n}^{\circ} 185,1982$, pp. 61-71.

(3) ESBERT, ROSA M $M^{\mathrm{a}}$ y MARCOS, ROSA Ma.: La deterioración de las Piedras de la Catedral de Oviedo. $2^{\text {a }}$ Parte: Formas y Fenómenos de alteración. Materiales de C'onstrucción, $\mathrm{n}^{\circ} 186,1982$, pp. 79-88.

(4) GAUSSORGUES, GILBERT.: La Thermographie Infrarouge. $3^{\text {a }}$ Edición. Téchnique et Documentation. Paris 1989.

(5) GAYO, E.; PALOMO, A.y MACÍAS A.: La termografia infrarroja: posibilidades y aplicación al estudio superficial de los materiales. Materiales de Construcción, $\mathrm{n}^{\circ} 227,1992$, pp. $5-14$.

(6) SERACINI, MAURIZIO: La termovisione come estrumento di indagine non invasiva nella diagnostica architettonica Atti del $1^{\circ}$ convegno nazionale ASS.I.R.CO. ASS.I.R.CO. Verona, Octubre 1981.

(7) NAUTIYAL, A.R.: Leaf Spectral Signatures as an Index of Biomass Production Potential in TreeSpecies. International Agrophysics, n³, 1987, pp. 31-33.

(8) RIORDAN, C ET AL. : Spectral Solar Radiation Data Base at SERI, Solar Energy, n 42,1989 , pp.67-79. 